\title{
Evaluation of High-Level Nuclear Waste Tanks Having a Potential Flammable Gas Hazard
}

\author{
G. D. Johnson
}

DE\&S Hanford, Inc.

W. B. Barton

R. C. Hill

Lockheed Martin Hanford Corporation

J. W. Brothers

S. A. Bryan

P. A. Gauglitz

L. R. Pederson

C. W. Stewart

Pacific Northwest National Laboratory

L. M. Stock

Consultant

Date Published

February 1997

To Be Presented at

Waste Management '97

Tucson, Arizona

March 2-6, 1997

Prepared for the U.S. Department of Energy

Office of Environmental Restoration and Waste Management

Project Hanford Management Contractor for the

U.S. Department of Energy under Contract DE-AC06-96RL13200

Copyright License By acceptence of this article, the publisher and/or recipient acknowledges the

U.S. Government's right to retain a nonexclusive, royalty-free license in and to any copyright covering this paper.

Approved for Public Release; distribution is unlimited 
LEGAL, DISCLAIMER

This report was prepared as an account of work sponsored by an agency of the United States Government. Neither the United States Government nor any agency thereof, nor any of their employees, nor any of their contractors, subcontractors or their employees, makes any warranty, express or implied. or assumes any legal liability or responsibility for the accuracy, completeness, or any third party's use or the results of such use of any information, apparatus, product, or process disclosed, or represents that its use would not infringe privately owned rights. Reference herein to any specific commercial product, process, or service by trade name, trademark, manufacturer, or otherwise, does not necessarily constitute or imply its endorsement, recommendation, or favoring by the United States Government or any agency thereof or its contractors or subcontractors. The views and opinions of authors expressed herein do not necessarily state or reflect those of the United States Government or any agency thereof.

This report has been reproduced from the best available copy.

Printed in tho United States of Americs

DISCLM-2.CHP (1-91) 


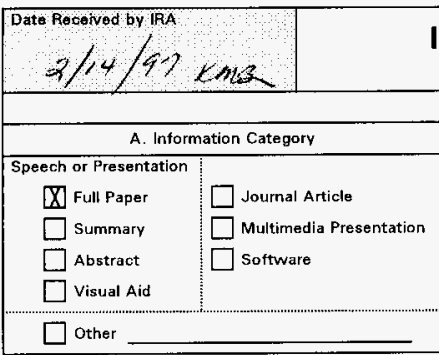

D. Document Title

B. Document ID Number (include rev., vol., etc.)

HNF-SA-3127-FP

C. List attachments (i.e., copyright permission, copyright transfer)

Evaluation of High-Level Nuclear Waste Tanks Having a Potential Flammable Gas Hazard

F. New or novel (patentable) subject matter?
If "Yes", has disclosure been submitted by WHC? [N] No or Yes

$\square$ No or Yes If "Yes", Disclosure No(s):

H. Copyrights? $\mathbb{N}$ No or Yes If "Yes", attach permission.

2. COMPLETE THIS SECTION FOR ALL DOCUMENTS REQUIRING SUBMISSION TO OSTI

\begin{tabular}{|c|c|c|c|}
\hline A. Unclassified Category & $U C-\therefore 0^{\circ}$ & B. Budget \& Reporting Code & $\mathrm{B} \& \mathrm{R}-E 2 y-201$ \\
\hline
\end{tabular}

A. Titile of Journal

4. COMFLETE THIS SECTION ONLY FOR A SPEECH OR PRESENTATION

\begin{tabular}{|c|c|c|}
\hline \multicolumn{2}{|c|}{$\begin{array}{l}\text { A. Title for Conference or Meeting } \\
\text { Waste Management } 97\end{array}$} & $\begin{array}{l}\text { B. Group or Society Sponsoring } \\
\text { Waste Management '97, University of Azizona }\end{array}$ \\
\hline $\begin{array}{l}\text { C. Date(s) of Conference } \\
\text { or Meeting }\end{array}$ & & E. Will material be published in proceedings? $y$ No or Yes \\
\hline March 1997 & Tucson, $A Z$ & Will material be handed out? \\
\hline
\end{tabular}

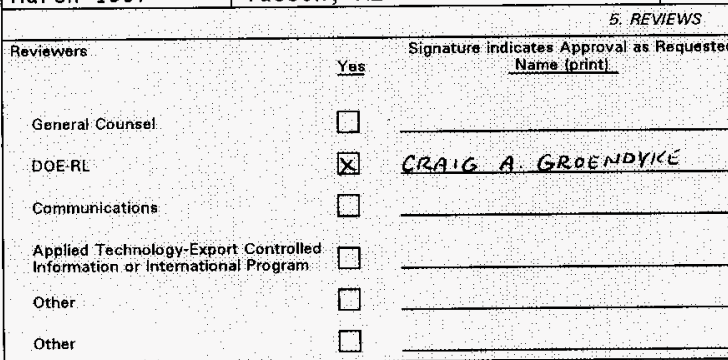

6. Applied Technology Material Referenced

\begin{tabular}{|c|c|c|}
\hline & {$[X]$ No } & $\square$ Yes \\
\hline 7. Release Level & & \\
\hline & {$[\mathrm{X}]$ Public } & | Limited Distribution \\
\hline
\end{tabular}

8. Author/Requestor

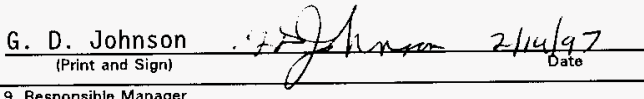

9. Responsiblo Manager

G. D. Johnson

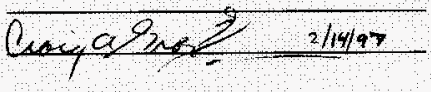
Uimited Use Info: dicated: Signatureloate

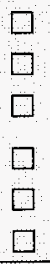

INFORMATION RELEASE ADMINISTAATION APPROVAL

IRA Approval is required before release. Release fo contingent upon resolution of mandatory comments. NOTE This blonk for TRA use only.

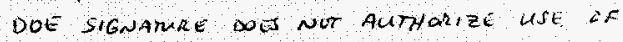

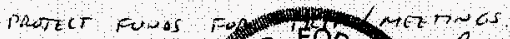

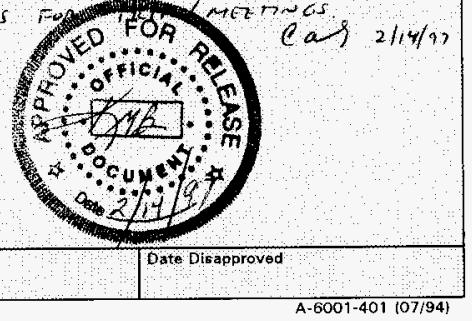


HNF-SA-3127-FP

Document iD Number

TO LEGENOS/NOTICES/MAKKINGS (Required bV WHC-CM-3-4 or Reviewer) Reviewer indicates applicable markings to be affixed or removed

Afflx Romove Hitials:

Applied Techiology

11. MANDATORY COMMENTS ILst only mandatory oomments here

to the author.)

12. ADDITONAC NFOAMATTON/COMMENTS:
Availabilty-ost

Avaliability ESTSC

Availability - NTIS

Business-Sensitive Information

Computer Software Notlce

Copyright License Notice

Export Controlled Information

Legal Disoläimer

Limited Disclosure. All other oomments shall be made on the document and returned

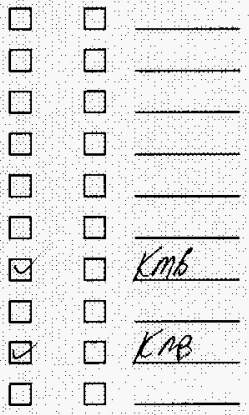

\begin{tabular}{lll}
\hline & \\
\hline &
\end{tabular}
Official Uae Only

Patent Status

Predecisional Infomation

Programmatic Notice

Proprietary lnformation

Purpose and Use

Thesis/Dissertation

Trademark Disclaimer

Other:
Atfix Remove Inltials

$\square \square$

$\square$

$\square$

$\square$

$\square$

$\square \quad \square$

$\square \quad \square$

$\square$

$\square$

a

Reviewer (Print \& Sign)

\begin{tabular}{|c|c|c|}
\hline RPeviewer: & Date & $\begin{array}{l}\text { Resolved by Author/Requestor } \\
\text { (Print \& Sign) }\end{array}$ \\
\hline & & \\
\hline & & \\
\hline & & \\
\hline & & \\
\hline & & \\
\hline & & \\
\hline & & \\
\hline$\because$ & & \\
\hline $\begin{array}{l}\because: \\
\vdots: \\
:\end{array}$ & & \\
\hline & & \\
\hline & & \\
\hline & & \\
\hline & & \\
\hline & & \\
\hline
\end{tabular}


HNF-SA-3127-FP

\title{
EVALUATION OF HIGH-LEVEL NUCLEAR WASTE TANKS HAVING A POTENTIAL FLAMMABLE GAS HAZARD
}

\begin{abstract}
In 1990 the U.S. Department of Energy declared an unreviewed safety question as a result of the behavior of tank 241-SY-101. This tank exhibited episodic releases of flammable gases that on a couple of occasions exceeded the lower flammability limit of hydrogen in air. Over the past six years a considerable amount of knowledge has been gained about the chemical and physical processes that govern the behavior of tank 241-SY-101 and the other tanks associated with a potential flammable gas hazard. This paper presents an overview of the current understanding of gas generation, retention, and release and covers the results of direct sampling of the tanks to determine the gas composition and the amount of stored gas.
\end{abstract}

\section{INTRODUCTION}

High-level radioactive waste has been stored in large underground tanks at the U.S. Department of Energy's Hanford Site in southeastern Washington State, some since 1944. Approximately 285 million liters of caustic waste is contained in 177 carbon-slecl tanks. Waste forms include liquids, slurries, salt cake and sludges.

Flammable gases, such as hydrogen and ammonia, are generated in the radioactive waste. These gas mixtures also contain an oxidizer (nitrous oxide) and an inert component (nitrogen). Some wastes retain the gas mixture until a fairly large amount builds up, then a short-term release occurs into the tank headspace. Such a release can result in a flammable concentration in the tank headspace. Then the only remaining element required for a deflagration is an ignition source present at the time of the gas release. This paper reviews the progress made in cvaluating the flammable gas safety issue, with an emphasis on understanding the processes for gas generation, retention, and release.

\section{NATURE OF HIGH-LEVEL WASTE}

Of the 177 high-level waste tanks at the Hanford Site, 149 are classified as single-shell tanks and 28 as double-shell tanks. The type of waste in the single-shell tanks is classified as dilute complexed waste, noncomplexed waste, and double-shell slurry feed. The dilute complexed waste has a high organic carbon content including the complexants ethylenediaminetetraacetic acid (EDTA) and hydroxyethylethylenediaminetriacetic acid (HEDTA). Non-complexed waste refers to general waste from Hanford Site operations that does not contain complexants. Double-shell slurry feed is waste concentrated in the evaporator until it has almost reached the sodium aluminate saturation boundary.

The doublc-shell tanks of concern contain double-shell slurry, which was produced by evaporation of singleshell tank waste. The slurry contains high amounts of hydroxide, nitrate, and aluminate and is more concentrated than the double-shell slurry feed. Some tanks also contain waste called complexed concentrate, which has significant organic concentrations

\section{UNDERSTANDING THE GENERATION OF GASES}

Hydrogen is produced by the radiolysis of water and the thermal and radiolytic reactions involving organic solutes. ${ }^{1}$ Hydrogen radicals are formed directly from the radiolysis of water, and the abstraction of a hydrogen atom from an organic solute also yields molecular hydrogen. Capture of the hydrated electron by 
the nitrate ion and capture of the hydrogen radical by the nitrite ion dominate radiolytic reactions in Hanford Site wastes. Reactions involving the nitrite ion lead to formation of most of the nitrogen-containing gases (nitrogen, nitrous oxide, and ammonia) by the thermally activated and radiolytic pathways. In the absence of radiation, the aluminate ion is needed to catalyze composition reactions through formation of a trihydroxynitritoaluminum complex, which acts an $\mathrm{NO}+$ donor. ${ }^{2,3}$ Active nitrogen oxide radicals are formed radiolytically without aluminate. The reaction of active nitrogen oxides with organic radicals results in formation of several compounds, including oximes $(\mathrm{RCH}=\mathrm{NOH})$ that can be hydrolyzed to form an aldehyde plus hydroxylamine. Further reaction of hydroxylamine leads to the formation of molecular nitrogen, nitrous oxide, and ammonia. Other aldehydic aging products, such as glyoxylate, are also important sources of hydrogen. ${ }^{4}$

Gas generation in actual Hanford Site tank. waste was evaluated using samples taken from tank 241-SY-1035 and a sample taken from tank $241-S Y-101 .^{6}$ These studies provide an important complement to the results of mechanistic studies using simulants. Because of the complexity of actual waste mixtures containing perhaps dozens of different organic constituents and fragments (some of which have not been identified), no simulant is likely to precisely match the gas generation behavior of actual wastes. It should be noted that we have over an $80 \%$ accountability of the organic compounds for tanks $241-S Y-103$ and $241-S Y-101$.

Thermal and self-irradiation gas generation rates for the waste material from tank 241-SY-103 were determined at temperature of $60^{\circ} \mathrm{C}$ to $120^{\circ} \mathrm{C}\left(140^{\circ} \mathrm{F}\right.$ to $\left.248^{\circ} \mathrm{F}\right)$. Themally activated reactions were dominant in this temperature range. Overall gas generation rates followed standard Arrhenius behavior. Activation energies were determined for overall gas generation $(96.3 \pm 6.3 \mathrm{~kJ} / \mathrm{mol})$, hydrogen $(91.3 \pm 9.0$ $\mathrm{kJ} / \mathrm{mol})$, nitrogen $(83.7 \pm 10.2 \mathrm{~kJ} / \mathrm{mol})$, and nitrous oxide $(116.7 \pm 9.4 \mathrm{~J} / \mathrm{mol})$. Nitrous oxide generation was favored at the higher reaction temperatures, while hydrogen generation was favored at the lower temperatures that are similar to those at which wastes are stored.

Radiolytic gas generation yields were determined for tank 241-SY-103 samples using an external radiation source and the deviation of gas generation rates measured at ambient temperature from extrapolated Arrhenius behavior. G-values (molecules per $100 \mathrm{eV}$ of energy deposited) were measured for each gas component generated. The average value for $\mathrm{G}\left(\mathrm{H}_{2}\right)$ was $0.14( \pm 0.02)$ molecules $/ 100 \mathrm{eV}$ for eight independent experiments representing data taken at temperatures ranging from $60^{\circ} \mathrm{C}$ to $75^{\circ} \mathrm{C}\left(140^{\circ} \mathrm{F}\right.$ to $\left.167^{\circ} \mathrm{F}\right)$. The average value for $\mathrm{G}\left(\mathrm{N}_{2} \mathrm{O}\right)$ was $0.033( \pm 0.009)$ at $60^{\circ} \mathrm{C}\left(140^{\circ} \mathrm{F}\right)$. The numbers in parentheses represent one standard deviation. Because of the small value for $\mathrm{G}\left(\mathrm{N}_{2} \mathrm{O}\right)$, it was not possible to measure a significant radiolytic increase for this product over the thermal contribution at $75^{\circ} \mathrm{C}\left(167^{\circ} \mathrm{F}\right)$ or above.

The gas generation tests using the waste sample from tank $241-S Y-101$ were performed in the approximate temperature range of $65^{\circ} \mathrm{C}$ to $100^{\circ} \mathrm{C}\left(149^{\circ} \mathrm{F}\right.$ to $\left.212^{\circ} \mathrm{F}\right) .^{6}$ Overall rates of gas generation for tank

$241-S Y-101$ waste samples were remarkably similar to results reported for tank 241-SY-103 wastes. The hydrogen generation rates for tank $24 \mathrm{l}-\mathrm{SY}$ - 101 for the first 10 days of tests performed at $100^{\circ} \mathrm{C}\left(212^{\circ} \mathrm{F}\right)$ $(0.75 \mathrm{~mole} / \mathrm{kg} / \mathrm{day})$, for example, are statistically indistinguishable from the kinetic data from tank 24l-SY-103 interpolated to that temperature. ${ }^{5}$

The estimated radiolytic yield of hydrogen, based on laboratory data for tank 241-SY-103 wastes and a correlation developed by Meisel, ${ }^{1}$ is as follows:

$\mathrm{G}\left(\mathrm{H}_{2}\right)=0.031+0.15 \times \mathrm{TOC}(\mathrm{wt} \%)$ molecules $\mathrm{H}_{2} / 100 \mathrm{eV}$.

Significant differences exist in the composition of the waste in the various Hanford Site waste tanks. As a result, gas generation behavior is expected to vary considerably. In waste mixtures studied in laboratory tests, most organic fraction derived from chelator and chelator fragments, which dissolved in the liquid 
fraction. Other wastes contain solvents that are largely insoluble in the liquid fraction and may decompose by totally different pathways. Laboratory gas generation studies using actual waste mixtures that represent different waste classes can significantly enhance the ability to estimate gas generation behavior in Hanford Site wastes. It is expected that as the organic chelating agents degrade, the composition and amount of gas produced will change. The generation behavior in such tanks may approach that of waste tanks that did not receive the organics, but further work is still needed to verify this situation.

\section{UNDERSTANDING GAS RETENTION}

Retained bubbles provide the primary mechanism for storing large quantities of flanmable gases in tank waste and for releasing it rapidly. The principal mechanisms of bubble retention can be grouped into three categories: bubbles retained by the strength of the waste material, bubbles retained by capillary forces, and bubbles retained by direct attachment to particles. In layers of materials, bubble retention is dominated by the waste strength and capillary forces; armored bubbles play a minor role.

The distinction between yield strength and capillary force retention depends on a Bond number. ${ }^{7,8,9}$ This dimensionless group contains two parametcrs: a ratio of gravitational force to surface tension force and a ratio of waste strength force to surface tension force.

$$
\frac{\text { Gravitational force }}{\text { Surface tension force }}=\frac{\Delta \mathrm{pghD}_{\text {particle }}}{4 \gamma} \text {. }
$$

$$
\frac{\text { Strength force }}{\text { Surface tension force }}=\frac{\tau_{s} D_{\text {particle }}}{4 \gamma}\left(\frac{A_{2}}{A_{1}}\right) \text {. }
$$

The surface tension force in these dimensionless groups reflects the resistance the bubble experiences as it seeks to move between particles. Hence, the appropriate length scale is the pore-throat diameter. For beds of packed particles, the median pore-throat diameter is roughly one-third the particle diameter. ${ }^{10}$ The actual pore-throat diameter (which is a distribution of sizes) can vary by an order of magnitude depending on the particle packing. For the purpose of this scaling analysis, the pore-throat diameter is approximated as the particle diameter, $D^{\text {particle }}$. In the first dimensionless parameter, $\Delta p$ is the density difference between the settled solids and the liquid, $g$ is the gravitational acceleration, and $h$ is the depth below the top of the settled solids. In the second parameter, the constant $A_{2} / A_{1}$ is a ratio of areas that resulted from a scaling analysis, ${ }^{8}$ and $\tau_{s}$ represents the shear strength of the material. Although it is expected that tensile and shear strengths are important in the growth of bubbles, the two measures of strength are commonly directly related (see reference 8 for a discussion of tensile and shear strength measurements).

The two parameters described above define the transition between two regimes of bubble retention: particledisplacing bubbles that are retained by yield strength forces and interstitial-liquid-displacing bubbles that finger between the particles composing the particulate media. Figure 1 shows the shape of subble is both of these regimes. ${ }^{8,9}$ When particle-displacing bubbles grow in a deformable material such as a bentonite clay or actual waste sludge, the dominant factors controlling their growth are surface tension forces, which seek to keep the bubbles round, and the strength of the material that the bubble must overcome to displace the particles. Simple scaling of the relative importance of sludge strength to surface tension gives the following dimensionless group that governs bubble growth in deformable materials: 
$\frac{\text { Strength force }}{\text { Surface tension force }}=\frac{\tau_{s} D_{\text {bubble }}}{\gamma}$

where $D_{\text {bubble }}$ is the bubble diameter. In this case, the surface tension force, $\gamma$, is related to the bubble size so that the bubble diameter, $D_{\text {bubbie }}$ is the appropriate length scale. Again, for this scaling, the strength of the material is chosen to be represented by the shear strength. This simple scaling assumes that the particles composing the waste are sufficiently small (small Bond number) that the bubbles never finger between the particles. The shear and tensile strengths of bentonite clay sludges decrease with increasing gas bubble content, ${ }^{8}$ a detail this simple scaling analysis neglects.

When surface tension dominates, the bubble shape is round. When the waste strength dominates, the bubbles grow by displacing the weakest material adjacent to the bubble. In this case, if any small nonuniformity exists in the material, the bubbles will follow that path and evolve into some dendritic shape. Although the overall shape may be dendritic, surface tension will dominate on a sufficiently small scale, and the interface between the gas and waste should be smoothly curved.

Figure 2 shows the different regimes of bubble retention, and the solid curve denotes the transition between interstitial-liquid-displacing bubbles and particle-displacing bubbles. ${ }^{9}$ The particle-displacing bubbles are retained by yield strength forces, and the interstitial-liquid-displacing bubbles are retained by capillary forces. The particle-displacing region, within the solid curve of Figure 2, is further subdivided. The figure also shows the characteristic shape of bubbles in the different areas of the plot.

\section{UNDERSTANDING THE RELEASE OF STORED GAS}

The free-gas release mechanisms currently considered most credible are buoyancy-induced displacement, percolation of dendritic bubbles, and mechanical disruption. ${ }^{11}$ Disruptions include local penetration (for example, core sampling), removal of waste by salt well pumping of liquid or sluicing of solids, addition of liquid that might dissolve surface solids, and severe seismic events. Only rollover and seismic disnuption are capable of a rapid release of a major fraction (approximately 50 percent) of the stored gas volume. Dendritic bubble percolation yields small, though possibly rapid, releases. Disruptions release gas mainly from the region being disturbed. Local penetrations cause only small releases. Salt well pumping may release a large fraction of stored gas, but the release occurs slowly over the entire campaign of one to two years. Likewise, most proposed retricval scenarios should release essentially all insoluble retained gas, but the release rate follows the progress of the operation.

Buoyant displacement is an instability event where the settled solids layer accumulates enough gas to become buoyant with respect to the supernatant liquid above it. When this happens, the buoyant solids bob to the surface, trading places with the liquid. If sufficient mechanical energy is released during the rollover, the solid-liquid matrix containing the gas is disnipted, and some stored gas is released. The amount of energy released increases with the depth of the supernatant. It has been found both analytically and experimentally that, for typical tank conditions, the supernatant liquid layer must be at least half the depth of the solids layer for a significant gas release. This condition only exists in certain double-shell tanks. Without sufficient supernatant liquid, the buoyant instability occurs very gently, if at all, and no gas is released. This is true in single-shell tanks. 


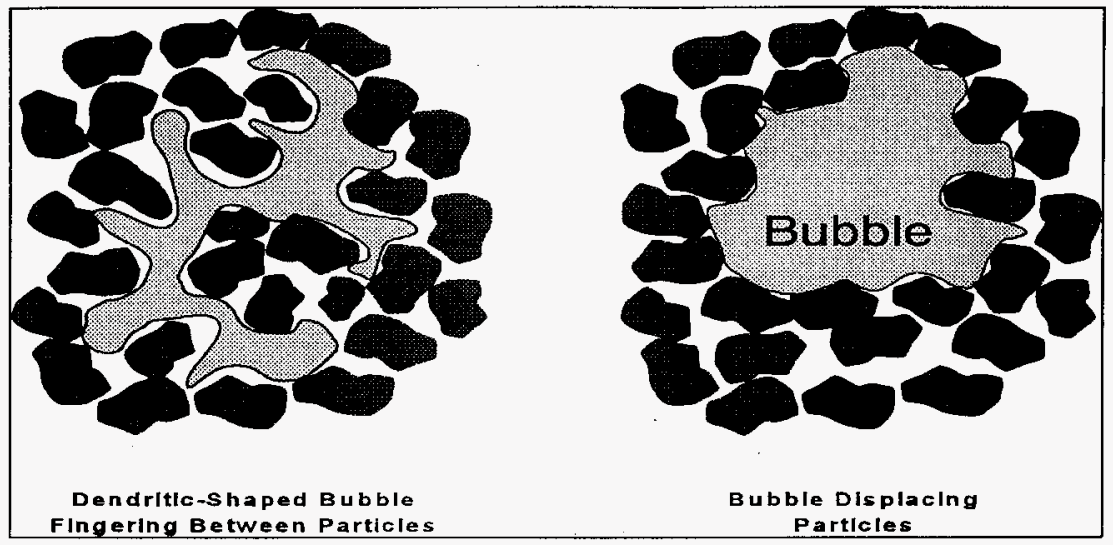

Figure 1. Schematic of Bubble Displacing Particles and a

Dendritic Bubble Fingering Between Waste Particles.

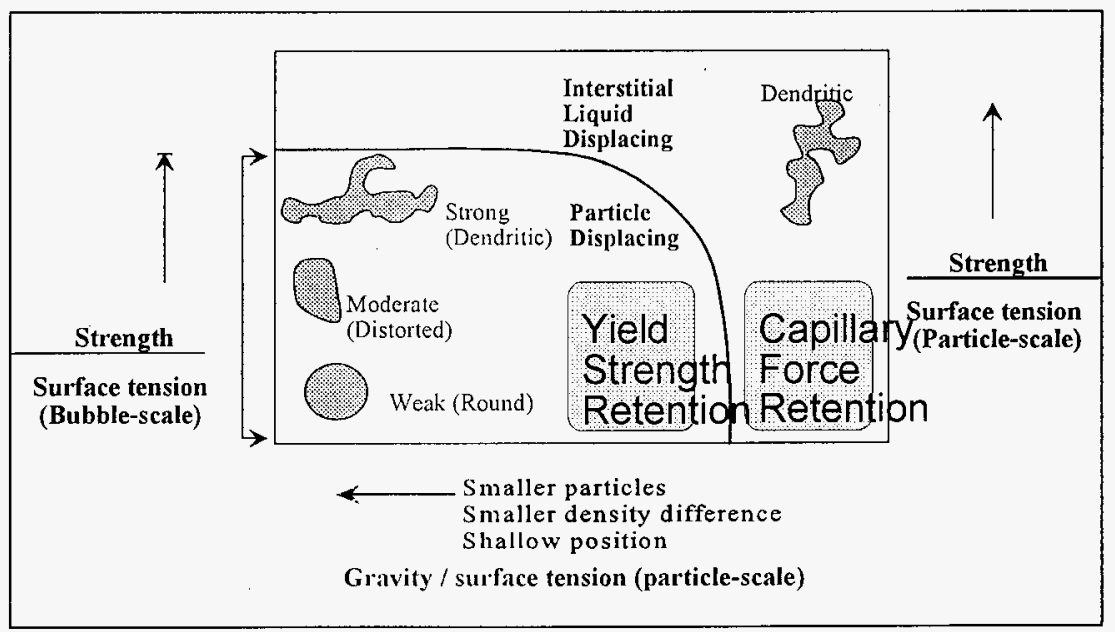

Figure 2. Plot Showing the Location of Different Bubble Retention Regimes. 
The gas release histories of the double-shell tanks subject to buoyant displacement ${ }^{12}$ suggest that tank 241-SY-101 was unique in releasing 120 to $220 \mathrm{~m}^{3}$ of gas, or 25 to 50 percent of its retained gas, approximately each 100 to 150 days. In contrast, the next highest release fractions are 15 to 25 percent in tanks 241-AW-101 and 241-AN-105. Tanks 241-SY-103, 241-AN-103, and 241-AN-104 released 5 to 12 percent of their retained gas on a random schedule. The actual release volumes are 26 to $40 \mathrm{~m}^{3}$ in tanks 241-AN-104 and 24l-AN-105 and 14 to $24 \mathrm{~cm}^{3}$ in the other three tanks. Only the gas releases in tank $241-\mathrm{SY}-101$ were sufficiently large to make the tank headspace gas mixture flammable.

Percolation describes the situation where dendritic bubbles grow into each other, connect, and rapidly rise up until a new equilibrium is reached or the gas escapes through the waste surface. The vertical extent of a connected dendritic region is limited by the balance of hydrostatic pressure with the capillary pressure and the yield strength of the material. Diffusional and probabilistic arguments limit the horizontal extent. Gas retained as a particle-displacing dendritic bubble potentially causes the largest release because the solids collapse as the bubble rises. Howcrer, calculations indicate these releases are limited to a few cubic meters at most.

At most, a local penetration disruption will release gas from the material actually disturbed by the penetration. The liquid surrounding a penetration maintains the hydrostatic pressure, and no "pressure sink" to the atmosphere is formed that could scavenge the gas from a wide region. Because of the limited volume of a connected source region, described above, local disruptions do not trigger large gas releases when penetrating dendritic bubbles, and no instance has been observed of a penetration such as core sampling triggering a buoyant rollover event in a double-shell tank.

Salt well pumping is the process of renoving free and interstitial liquid. This process has been or is scheduled to be performed on most Hanford Site single-shell tanks to prevent future leaks. In salt cake tanks where gas is retained as pore-filling bubbles, salt well pumping releases gas by uncovering trapped gas bubbles and by reducing the hydrostatic pressure, which causes further release by percolation. In sludge tanks where gas is stored as particle-displicing bubbles, very little gas may be released, although the initial gas volume may expand under reduced hydrostatic pressure. In either case, the gas release rate is slow and partly controlled by the pumping rate, and gas accumulation is permanently prevented in the portion of the waste above the final liquid horizon. A potential hazard peculiar to salt well pumping is a high ammonia concentration as the dissolved gas cvaporates from the pores of newly exposed waste.

A severe seismic event has the potential to disturb all tank contents, possibly to the point of yielding and allowing a large fraction of the trapped gas to escape rapidly. An approximate (though probably conservative) calculation indicates that a 100 -year earthquake $(0.22 \mathrm{~g})$ deposits about the same amount of energy in double-shell tank waste as was released in the large rollover events of tank 241-SY-101. These events released on the order of 50 percent of the stored gas. If the analogy holds, a 100 -year earthquake might cause a gas release of similar magnitude. For single-shell tank waste with yield strength 1,500 to $3,000 \mathrm{~Pa}, \mathrm{a} 1,000$-year earthquake (assumed to be $0.35 \mathrm{~g}$ ) is required to deposit the same relative energy.

The current understanding of the physics of gas retention and release in Hanford Site waste tanks leads to the conclusion that buoyancy-induced displacement is the only credible mechanism for a large, rapid, spontaneous gas release. An encrgetic relcase can only occur with a supernatant liquid layer approximately as thick as the gas-bearing solids layer. This condition exists only in double-shell tanks. Severe seismic events could potentially release as much gas as rapidly as did the large rollovers in tank 24 I-SY-101. A 100-year earthquake might do this in a double-shell tank, but a 1,000-year event would be required to produce the same result in an singlc-shell tank. No other credible mechanisms are likely to release flammable gas in an amount and at a rate that would pose an immediate hazard. 
HNF-SA-3127-FP

\section{RESULTS OF DIRECT SAMPLING OF WASTE TANKS}

\section{Gas Composition}

Gas compositions in tank 241-SY-101 are well known. Pasamehmetoglu ${ }^{13}$ analyzed a large body of gas composition data and provided a best and a conservative estimate for the composition of gases released during a gas-release event. The results are shown in Table I. Hydrogen is less than one-third the total gas volume. Nitrogen and nitrous oxide are similar in concentration, and ammonia is also a principal component.

Table I. Estimales of the Overall Composition of Gnses at $46{ }^{\circ} \mathrm{C}$ in Tank $241-S Y-101$.

\begin{tabular}{|l|c|}
\hline \multicolumn{1}{|c|}{ Component } & Estimated Mole \% \\
\hline Hydrogen & 29 \\
\hline Nitrous oxidc & 24 \\
\hline Ammonia & 11 \\
\hline Nitrogen & 33 \\
\hline Methane & 0.4 \\
\hline Carbon monoxide & 0.2 \\
\hline Water & 2.4 \\
\hline
\end{tabular}

In-tank gas composition data were collected by mass spectrometry analysis of grab samples taken from the headspace of various Hanford Site tanks. ${ }^{4}$ A particularly wide variation in the ratio of hydrogen to nitrous oxide concentrations was noted among tanks. from a high of 33 for tank 24l-AW-101 to a low of 0.40 for tank 24l-U-105. In laboratory tests with simulated and actual wastes, hydrogen yields were enhanced and nitrogen-containing gas yields were depressed by the presence of oxygen. Because dilution with air prevents the determination of oxygen concentrations in grib samples, this relationship could not be verified. Gas composition results determined in laboratory lests with waste samples agreed within experimental error with grab sample composition results.

Development of a new device, called the retaincd gas sampler, enables the composition of gases trapped in Hanford wastes to be determined without dilution by air. Tank 241-AW-101 was the first tank to be sampled using this device. The major species found were nitrogen, ammonia, hydrogen, and nitrous oxide. Insoluble gases in tank 241 -AW-101 wastes range from 670 to $4,100 \mu$ moles per liter. Nitrogen made up more than $50 \mathrm{~mol} \%$ of the gases found.

\section{Evaluation of Stored Gas Volume}

Evaluating the flammable gas hazard in a particular tank requires an estimate of the volume of gas retained, the fraction of the retained gas that can be released, and the speed with which it might enter the tank headspace. One method of obtaining somc of this information is by measuring the void fraction at specific locations in a tank and then calculating the total gas volume. Table II shows the data taken in six Flammable Gas Watch List double-shell tanks and the resulting calculated gas volume data. ${ }^{12}$ Tank 241-AN-103 contained the most gas; it was comparable to tank 241-SY-101 prior to mixing. Tank 241-AW-101 contained the least gas in the nonconvective layer but was very similar to tanks 241-AN-104, 241-AN-105, and 241-SY-103. 
Table II. Calculated Gas Volume in Six Flammable Gas Watch List Tanks.

\begin{tabular}{|l|c|c|c|c|c|c|}
\hline \multicolumn{1}{|c|}{ Tank } & $241-\mathrm{SY}-101$ & $241-\mathrm{SY}-103$ & 241 -AW-101 & 241 -AN-103 & 241-AN-104 & 241-AN-105 \\
\hline $\begin{array}{l}\text { Gas volume (m }{ }^{3} \text { at STP) } \\
\text { from VFI measurements }\end{array}$ & $218 \pm 52$ & $192 \pm 73$ & $209 \pm 46$ & $464 \pm 30$ & $213 \pm 41$ & $180 \pm 26$ \\
\hline $\begin{array}{l}\text { Level response (dL/dP) } \\
\text { (cm/kPa) from } \\
\text { correlation of level and } \\
\text { pressure measurements }\end{array}$ & $0.30 \pm 0.07$ & $0.14 \pm 0.04$ & $0.18 \pm 0.04$ & $0.518 \pm 0.02$ & $0.20 \pm 0.04$ & $0.14 \pm 0.02$ \\
\hline $\begin{array}{l}\text { Effective pressure } \\
\text { (atmosphere), relating the } \\
\text { level response above to } \\
\text { the reconciled gas } \\
\text { volume below }\end{array}$ & 1.39 & 1.71 & 1.61 & 1.58 & 1.77 & 1.82 \\
\hline $\begin{array}{l}\text { Reconciled gas volume } \\
\text { (m }{ }^{3} \text { at STP), derived } \\
\text { from both VFI } \\
\text { measurements and the } \\
\text { measured level response }\end{array}$ & $215 \pm 49$ & $167 \pm 39$ & $185 \pm 42$ & $497 \pm 22$ & $244 \pm 28$ & $180 \pm 35$ \\
\hline
\end{tabular}

STP $=$ standard temperature and pressure.

$\mathrm{VFI}=$ void fraction instrument

The waste height measurements taken in Hanford Site waste tanks often show a strong correlation to barometric pressure, indicating the presence of retained gas. This level response can be used to estimate the retained gas volume provided information about the pressure at which the gas is held is available. Such information is shown in the table and was used to provide a reconciled gas volume.

\section{Gas Release Events}

On-line gas monitors have been installed in 25 waste tanks. These monitors provide for continuous measurement of hydrogen and for periodic grab samples so other gases can be evaluated by mass spectrometry. To date only the double-shell tanks have exhibited episodic releases; results for 19 single-shell tanks have shown relatively consiant gis concentrations. Results of grab samples taken from 134 passively ventilated single-shell tanks showed that all tanks had flammable gas concentrations that were less that 25 percent of the lower flammability limit. ${ }^{1 / 4}$

A monitoring control limit has been established at 0.625 percent (by volume) hydrogen. This limit was determined from an analysis of a burn of the worsl-case gas composition; ${ }^{15}$ the limit takes into account the presence of other gases such as ammonia, methane, and nitrous oxide. For those tanks that exceed the monitoring limit, it will be necessaly to conduct an engineering study to determine whether any mitigative actions are required. To date three tanks have exceeded the limit. Tank 241-SY-101 had, on a couple of occasions, exceeded the lower flammability limit; a mixer pump is being used to prevent the large episodic gas releases. Two other tanks, $24 \mathrm{I}-\mathrm{AW}-10 \mathrm{l}$ and $241-\mathrm{AN}-105$, exceeded the monitoring limit but did not exceed the lower flammability level. Upgrades to the ventilation systems are being done for the tank farms containing these two tanks. 


\section{PATH FORWARD}

Although considerable understanding has been gained about the phenomena related to the flammable gas safety issue, there are still technical issues that need further evaluation. Considerable effort is needed to put this knowledge into the models and methods used to predict tank behavior. Additional data need to be obtained from various tanks to evaluate stored gas and gaseous evolution phenomena. One of the more important activities is updating the authorization basis for the tank farms. Both a basis for interim operation and a final safety analysis report have been submitted to the U.S. Department of Energy. Closure of the flammable gas unreviewed safety question is a critical item and comprises a significant part of the current program. Twenty-five tanks are currently on the Flammable Gas Watch List; the approach for adding and removing these tanks from the Watch List is being developed.

Analyzing tanks for episodic gas relcase behavior must be based on a total reconciliation of all available data on the given tank so that a consistent understanding of tank conditions is achieved. Behavioral models for gas retention and methods for predicting gas releases are being refined. These tools will be needed to resolve the unreviewed safety question and to remove lanks from the Watch List.

\section{REFERENCES}

1. D. MEISEL, C. D. JONAH, S. KAPOOR, M. S. MATHESON, and M. C. SAUER, "Radiolytic and Radiolytically Induced Generation of Gises from Synthetic Wastes," ANL-93/43, Argonne National Laboratory (1993).

2. E. K. BAREFIELD, D. BOATWRIGHT, A. DESHPANDE, F. DOCTOROVICH, C. L. LIOTTA, H. M. NEUMANN, and S. SEYMORE, "Mechanisms of Gas Generation from Simulated SY Tank Farm Wastes: FY 1994 Progress Repor1." PNL-10822, Pacific Northwest Laboratory (1995).

3. E. K. BAREFIELD, D. BOATWRIGHT, A. DESHPANDE, F. DOCTOROVICH, C. L. LIOTTA, H. M. NEUMANN, and S. SEYMORE, "Mechanisms of Gas Generation from Simulated SY Tank Farm Wastes: FY 1995 Progress Report," PNL-1 1247, Pacific Northwest National Laboratory (1996).

4. L. R. PEDERSON, and S. A. BRYAN, "Status and Integration of Studies of Gas Generation in Hanford Wastes," PNNL-11297, Pacilic Northwest Laboratory (1996).

5. S. A. BRYAN, C. M. KING. L. R. PEDERSON, S. V. FORBES, and R. L. SELL, "Gas Generation from Tank 241-SY-103 Wasle." PNNL-10978, Pacific Nortliwest National Laboratory (1996).

6. J. C. PERSON, "Effects of Oxygen Cover Gas and NaOH Dilution on Gas Generation in Tank 241-SY-101 Waste," WHC-SD-WM-DTR-043, Westinghouse Hanford Company (1996).

7. P. A. GAUGLITZ, L. A. MAHONEY, D. P. MENDOZA, and M. C. MILlER, "Mechanisms of Gas Bubble Retention," PNL-10120. Pacific Northwest Laboratory ( 1994).

8. P. A. GAUGLITZ, S. D. RASSAT. M R. POWELL, R. R. SHAH, and L. A. MAHONEY, "Gas Bubble Retention and its Elfect on Waste Properties: Retention Mechanisms, Viscosity, and Tensile and Shear Strength," PNL-10740. Pacilic Northwest Laboratory (1995). 
9. P. A. GAUGLITZ, S. D. RASSAT, P. R. BREDT, J. H. KONYNENBELT, S. M. TINGEY, and D. P. MENDOZA, "Mechanisms of Gas Bubble Retention and Release: Result for Hanford Waste Tanks 241-S-102 and 241-SY-103 and Single-Shell Tank Simulants," PNNL-11298, Pacific Northwest National Laboratory (1996).

10. F. A. L. DULLIEN, "Porous Media: Fluid Transport and Pore Structure," Academic Press (1992).

11. C. W. STEWART, M. E. BREWSTER, P. A. GAUGLITZ, L. A. MAHONEY, P. A. MEYER, K. P. RECKNAGLE, and H. C. REID, "Gas Retention and Release Behavior in Hanford Single-Shell Waste Tanks," PNNL-11391, Pacific Northwest National Laboratory (1996).

12. C. W. STEWART, J. M. ALZHEIMER, M. E. BREWSTER, G. CHEN, R. E. MENDOZA, H. C. REID, C. L. SHEPARD, and G. TERRPMES, "In Situ Rheology and Gas Volume in Hanford Double-Shell Waste Tanks," PNNL-11296, Pacific Northwest Laboratory (1996).

13. K. O. PASAMEHMETOGLU, "Analyses of Gas Composition and Relevant Gas Concentration Measurements for the Release Gas in Tank 241-SY-101," N6-CN-WT-SA-GR-004, Los Alamos National Laboratory (1994).

14. N. E. WILKINS, "Results of Vapor Space Monitoring of Flammable Gas Watch List Tanks," HNF-SD-WM-TI-797, Rev, 0, Fluor Danicl Hanford Company (1996).

15. D. J. SHERWOOD, "Flammable Gas Tank Safety Program: Technical Basis for Gas Analysis and Monitoring," Appendix A, WHC-SD-WM-ES-346, Rev. 0, Westinghouse Hanford Company (1995). 


\section{DISTRIBUTION}

\section{Number of Copies}

\section{OFFSITE}

1

L. M. Stock

6022 SW Texas Court

Portland, Oregon 97219

1 H. Babad

Babad Technical Services

2450 Cordoba Court

Richland, Washington 99352

\section{ONSITE}

3

U.S. Department of Energy. Richland Field office
J. M. Gray
S7-54
C. A. Groendyke
S7-54
D. H. Irby
S7 -54

6

DE\&S Hanford, Inc.
R. E. Bauer
S7-14
D. R. Bratzel
$57-14$
R. J. Cash
$57-14$
W. M. Funderburke
$\mathrm{R} 2-38$
T. C. Geer
$\mathrm{R} 2-38$
G. D. Johnson
S7-14

Lockheed Mart in Hanford Corporation
W. B. Barton
R2-11
R. C. Hil1
R1-51
A. M. Umek
S7-8I

5

Pacific Northwest National Laboratory

J. W. Brothers

K9-20

S. A. Bryan

$P 7-25$

P. A. Gauglitz

P7-41

L. R. Pederson

K2-44

C. W. Stewart

K7 -15

3 Lockheed Martin Services, Inc.

Central Files

A3-88

Document Processing Center

Rl-29 